Raviella Zgheib, Marc El Beyrouthy*, Youssef El Rayess, Mira Dahi, Nancy Nehme, Samar Azzi-Achkouty and Marcello Iriti*

\title{
Effect of geographical origin on yield and composition of cone essential oils of Cedrus libani A. Rich. growing in Lebanese protected areas and variability assessment in comparison with literature survey
}

https://doi.org/10.1515/znc-2019-0172

Received September 27, 2019; revised January 20, 2020; accepted January 21, 2020

Abstract: Gas chromatography-mass spectrometry analysis together with principal component analysis revealed that geographical origin influenced the yield and composition of the essential oils (EOs) extracted by hydrodistillation performed for $3 \mathrm{~h}$ using a Clevenger-type apparatus, from the cones of Cedrus libani A. Rich., growing wild at four Lebanese natural reserves and protected areas: Bsharri, Chouf, Ehden, and Tannourine, and from a cultivated cedar growing in Qartaba. Essential oil chemical variability established between the different studied provenances suggested the involvement of abiotic factors such as geographical conditions, cultivation conditions, soil composition, and environmental factors in the chemical polymorphism of $C$. libani cones EOs. $\alpha$-Pinene $/ \beta$ pinene characterized Ehden ( $\beta$-pinene 35.6\%/ $\alpha$-pinene $27.7 \%$ ), Chouf ( $\alpha$-pinene 37.3\%/ $\beta$-pinene $26.1 \%$ ), Bsharri ( $\alpha$-pinene $27.7 \% / \beta$-pinene $21.4 \%$ ), and Tannourine ( $\alpha$-pinene $25.1 \% / \beta$-pinene $16.0 \%$ ) samples, whereas Qartaba EO was distinguished by the dominance of myrcene

*Corresponding authors: Marc El Beyrouthy, Department of Agriculture and Food Engineering, School of Engineering, Holy Spirit University of Kaslik, B.P. 446, Jounieh, Lebanon, Phone: 009619220884 , Fax: 0096196008871 , E-mail: marcelbeyrouthy@usek.edu.lb; and Marcello Iriti, Department of Agricultural and Environmental Sciences, Milan State University, via G. Celoria 2, 20133 Milan, Italy, Phone: 0390250316766, E-mail: marcello.iriti@unimi.it.

https://orcid.org/0000-0002-5063-1236

Raviella Zgheib: Institut Jean-Pierre Bourgin, AgroParisTech, INRA, Université Paris-Saclay, RD 10, Route de Saint-Cyr, 78026 Versailles, France; and Ecole supérieure d'ingénieurs d'agronomie méditerranéenne, Université Saint Joseph de Beyrouth, Békaa, Lebanon

Youssef El Rayess and Samar Azzi-Achkouty: Department of Agriculture and Food Engineering, School of Engineering, Holy Spirit University of Kaslik, B.P. 446, Jounieh, Lebanon

Mira Dahi: Department of Sciences, Holy Spirit University of Kaslik, B.P. 446, Jounieh, Lebanon

Nancy Nehme: Faculty of Agricultural Engineering and Veterinary Medicine, Lebanese University, Dekwaneh, Lebanon
(30.6\%), $\alpha$-pinene(26\%), and limonene (14.1\%). Comparison with the existing literature reinforced the chemical variability of $C$. libani EOs. This current study helped the estimation of a best harvest location for a good EO quality production, resource optimization, and pharmacological properties evaluation, according to the market demand.

Keywords: Cedrus libani; chemical variability; essential oil; geographical location.

\section{Introduction}

Growing at a high altitude between 1200 and 2000 m, often in rocky and barely reachable locations, Cedrus libani A. Rich. is admired for its beauty and the imputrescibility of its wood [1]. Cedrus libani exists naturally in the Alaouite Mountains in Syria, in Toros Mountains in Turkey, and in the Coastal Mountains of Lebanon [2].

The cedar of Lebanon is mentioned 75 times in the Holy Bible [3]; owing to its majesty and its long life, this millennium tree represents the symbol of strength, stability, life, hope, freedom, continuity and eternity; hence, it is adopted as the national emblem of Lebanon [4].

Cedar of Lebanon is considered a tree of great historical and economic value providing a prized wood [5-7]. Cedrus libani essential oils (EOs) had a great usage in folk medicine. Since time immemorial, they were used to embalm and conserve the pharaohs of Egypt [3]. The existence of antimicrobial, antioxidant, larvicidal, and antiviral properties related to these oils has been proven in recent reports [2, 8-10].

Bearing in mind that a combination of more than one factor may affect the metabolomic profile of plants leading to specific EO chemical compositions and defining their biological properties [11-18], this present investigation aims to contribute to a better knowledge of the chemical composition of $C$. libani cones EOs and to follow the chemical variability according to region of harvest between cones of cedars growing wild at four Lebanese natural reserves and protected areas, Bsharri, Chouf, Ehden, and 
Tannourine, and cones of a cultivated cedar growing in Qartaba. Besides, the chemical diversity of the volatile components was described in comparison with the data available in the literature. In fact, EO chemical variability in response to biotic and abiotic pressures constitutes a significant correlation between chemical composition and bioactivity and procures a new source of information for the development of future optimal EO mixture.

To the best of our knowledge, studies investigating a detailed chemical characterization and polymorphism of Lebanese $C$. libani cones EOs, in relation to geographical location, have not been published to date. Furthermore, this is the first study occurring on different Lebanese natural reserves with a permission of harvest conferred by officials.

\section{Experimental}

\subsection{Plant material and EO extraction}

Cedrus libani cones were collected from cedars growing wild at four different Lebanese natural reserves and protected areas: Bsharri $(1950 \mathrm{~m})$ (Bsharri District/North Governorate), Ehden (1800 m) (Zgharta District/North Governorate), Tannourine (1850 m) (Batroun District/ North Governorate), and Chouf (1650 m) (Chouf District/ Mount Lebanon Governorate), and from a cedar cultivated at Qartaba (1200 m) (Jbeil District/Mount Lebanon Governorate).

The harvest was executed in September 2016, at $10 \mathrm{AM}$ of each sampling date.

Botanical identification of the plant samples was carried out by Dr. Marc El Beyrouthy according to the New Flora of Lebanon and Syria as described by Mouterde in 1983 [19]. A voucher specimen of each cones sample was deposited in the Herbarium of the Faculty of Agricultural and Food Sciences of Holy Spirit University of Kaslik, Lebanon, under the registry numbers MNI015a for the Bsharri cedars, MNI015b for the Ehden cedars, MNI015c for the Tannourine cedars, MNI015d for the Chouf cedars, and MNI015e for Qartaba cedars. Three hundred grams of C. libani cones was air dried in the absence of light at $4{ }^{\circ} \mathrm{C}$ for a period of 4 weeks. The EOs were extracted by hydrodistillation performed for $3 \mathrm{~h}$ using a Clevenger-type apparatus, according to the method described in the European Pharmacopoeia, 1997 [20]. The extracted oils were kept, measured, and stored at $4{ }^{\circ} \mathrm{C}$ in tightly closed glass vials until their analysis by gas chromatography-mass spectrometry (GC/MS). Essential oil content, expressed in $\mathrm{mL} / \mathrm{g}$, was evaluated by measuring the volume of oil extracted per weight of dried plant material.

\subsection{Essential oils analyses}

\subsubsection{GC analyses}

The GC analysis was carried out using a Thermo Electron Corporation apparatus (Agilent, Santa Clara, CA, USA) equipped with a flame ionization detector, a nonpolar HP-5MS (5\% phenylmethylsiloxane) capillary column (30 $\mathrm{m} \times 0.25 \mathrm{~mm}$ i.d., film thickness $0.25 \mu \mathrm{m}$ ), and a polar fused-silica HP Innowax capillary column (polyethylene glycol, $50 \mathrm{~m} \times 0.20 \mathrm{~mm}$ i.d., film thickness $0.20 \mu \mathrm{m}$ ) in order to confirm the identification of the components. The carrier gas was $\mathrm{He}$ at a rate of $1 \mathrm{~mL} / \mathrm{min}$. The oven temperature followed a gradient rising from $40{ }^{\circ} \mathrm{C}$ to $300^{\circ} \mathrm{C}$ at $5{ }^{\circ} \mathrm{C} / \mathrm{min}$ and finally held isothermal at $300{ }^{\circ} \mathrm{C}$ for $5 \mathrm{~min}$. Diluted $1-\mu \mathrm{L}$ samples $(1 / 100, \mathrm{vol} / \mathrm{vol}$ in pentane) were manually injected at $250{ }^{\circ} \mathrm{C}$ and in the splitless mode. Flame ionization detection was performed at $310{ }^{\circ} \mathrm{C}$.

\subsubsection{GC/MS analyses}

The GC/MS analyses were achieved using an Agilent Thermo Electron Corporation (Agilent, Santa Clara, CA, USA) apparatus coupled with Mass Detector 5975 and equipped with $7683 \mathrm{~B}$ auto sampler [injection of $1 \mu \mathrm{L}$ of each oil sample diluted in pentane $(1 / 100 \mathrm{vol} / \mathrm{vol})]$. A fused-silica capillary column HP-5MS $(30 \mathrm{~m} \times 0.25 \mathrm{~mm}$ i.d., film thickness $0.25 \mu \mathrm{m}$ ) and a fused-silica HP Innowax polyethylene glycol capillary column $(50 \mathrm{~m} \times 0.20 \mathrm{~mm}$ i.d., film thickness $0.20 \mu \mathrm{m}$ ) were used. The oven temperature program was identical to that described above ( $c f$. GC analyses). Helium was the carrier gas $(1 \mathrm{~mL} / \mathrm{min})$. The mass spectra were recorded at $70 \mathrm{eV}$. Ion source and transfer line temperatures were $310^{\circ} \mathrm{C}$ and $320^{\circ} \mathrm{C}$, respectively. The acquisition was recorded in full scan mode (50-400 amu).

\subsubsection{Identification and quantification of the components}

An $n$-alkane $\left(\mathrm{C}_{7}-\mathrm{C}_{25}\right)$ mixture was analyzed under the same experimental GC/MS conditions to calculate the retention indices (RIs). Identification of EO components was performed by comparing their mass spectra on both columns with those listed in the commercial mass spectral libraries NIST and Wiley 275 computer libraries, our home-made 
library constructed with pure compounds, and those from literature [21, 22], allowing a reliable confirmation of the identity of each component. A further identification was accomplished by comparing their RIs on both polar and apolar columns relative to the retention times of the series of $n$-alkanes $\left(\mathrm{C}_{7}-\mathrm{C}_{25}\right)$ with those from literature $[21,23]$ or with those of standard compounds available in our laboratories, obtained from Sigma-Aldrich (Germany). Standards of some EOs of known composition (such as the EO of Rosmarinus officinalis L. from Phytosun Aroms, Plélo, France) were also injected in similar conditions for the comparison of retention times $\left(t_{\mathrm{R}}\right)$ and mass spectra. In addition, the following standards were purchased from Sigma-Aldrich: $\alpha$-pinene, camphene, $\beta$-pinene, myrcene, limonene, borneol, terpinen-4-ol, $\alpha$-terpineol, verbenone, bornyl acetate, $\beta$-caryophyllene, $\gamma$-cadinene, $\delta$-cadinene, caryophyllene oxide, $\alpha$-cadinol, and $\beta$-bisabolol. Relative proportion of each compound was determined from the GC peak areas.

\subsection{Statistical analyses}

\subsubsection{Analysis of variance}

One-way analysis of variance (ANOVA) was applied in order to evaluate EO chemical variability according to geographical location and to identify where any difference may have existed between samples. Statistical analyses were performed using SPSS 16.0 software (SPSS Inc., Chicago, IL, USA). A probability value of $\mathrm{p} \leq 0.05$ was considered to highlight a statistically significant difference between oil samples.

\subsubsection{Principal components analysis}

Principal component analysis (PCA), a multivariate statistical technique that aims at reducing the multivariate space in which objects (oil samples) are distributed, was applied. This processing was performed using XLSTAT 2014.5.03 (Addinsoft, Paris, France).

\section{Results and discussion}

\subsection{Essential oils yield}

The average of EO yields from the cones of cedars harvested in triplicate from each site of different Lebanese geographical locations fluctuated between $0.16 \% \pm 0.02 \%$ and $0.54 \% \pm 0.1 \%$.

Cones of Chouf natural reserve presented the highest EO yield (0.54\%), followed by those harvested from Ehden $(0.29 \%)$, Bsharri $(0.25 \%)$, and Tannourine $(0.24 \%)$, whereas cones of the cultivated cedar from Qartaba exhibited the lowest EO yield (0.16\%). It can be concluded that EO yield varies according to the provenance.

According to Tumen et al. [24], oil yield was $0.37 \%$ in "'C. libani cones from Adana, Turkey. Yilmaz et al. in 2005 reported that the yield obtained from $C$. libani cones harvested from Başkonuş District, Turkey, was 1\% [25]. Loizzo et al. [8] in 2007 revealed that EO yield from cones of $C$. libani harvested from Hadath Eljebeh-Tannourine reserve was $0.41 \%$.

The difference in yield observed in our results between the different sites asserts EO chemical variability, which is favored by the existence of a wide variety of microclimatic zones distinguishing Lebanon. In fact, chemical variability does not only depend on genetic background, but it can be also affected by external conditions or ecological factors that can have effects on plant development and vegetative growth and have a direct impact on EO production, both quantitatively and qualitatively. Those extrinsic factors include oil composition, cultivation conditions, and geographical factors such as altitude and climatic factors (temperature, sunshine duration, wind regime, rainfall, humidity, etc.) $[16,26]$.

\subsection{Essential oils chemical characterization and polymorphism}

\subsubsection{Essential oil chemical composition}

The EOs extracted from the cones of $C$. libani constitute a mixture of 51 compounds, representing $95.2 \%$ to $99.9 \%$ of the total oil composition. Table 1 lists the average of the relative percentages of the constituents of the oils, collected in triplicate from each site of the five Lebanese locations during September 2016. Cedrus libani EO chemical compositions were distinguished by their wealth in $\alpha$-pinene $(25.1 \%-37.3 \%), \beta$-pinene $(6.4 \%-35.6 \%)$, myrcene (0\%-30.6\%), limonene (5.6\%-14.1\%), sclarene $(1.1 \%-$ $5.5 \%)$, abieta-8,11,13-triene $(2.2 \%-10.2 \%)$, kaur-16-ene $(3.5 \%-7.5 \%)$, and abieta-7,13-diene $(1.9 \%-7.5 \%)$, representing more than $5 \%$ of the total oil content in at least a sample, with a predominance of $\alpha$-pinene, $\beta$-pinene, and myrcene (Table 1). 
Table 1: Chemical composition of the EOs extracted from the cones of $C$. libani harvested from different Lebanese geographical locations.

\begin{tabular}{|c|c|c|c|c|c|c|c|}
\hline$\left.\mathbf{R}\right|^{\mathbf{a}}$ & $\mathbf{R} \mathbf{I}^{\mathbf{b}}$ & Region of harvest & Bsharri & Ehden & Tannourine & Chouf & Qartaba \\
\hline & & Date of harvest & Sep-16 & & & & \\
\hline & & Essential oil yield (\%) & $0.25 \pm 0.02$ & $0.29 \pm 0.04$ & $0.24 \pm 0.01$ & $0.54 \pm 0.01$ & $0.16 \pm 0.02$ \\
\hline & & Chemical compound & & & & & \\
\hline 933 & 1076 & $\alpha$-Pinene & $27.7 \pm 0.4$ & $27.7 \pm 0.3$ & $25.1 \pm 0.8$ & $37.3 \pm 0.4$ & $26.0 \pm 1.8$ \\
\hline 947 & 1076 & Camphene & $1.0 \pm 0.0$ & $1.3 \pm 0.3$ & $0.9 \pm 0.1$ & $1.8 \pm 0.0$ & $1.1 \pm 0.1$ \\
\hline 980 & 1118 & $\beta$-Pinene & $21.4 \pm 0.4$ & $35.6 \pm 1.8$ & $16.0 \pm 0.5$ & $26.1 \pm 0.1$ & $6.4 \pm 0.4$ \\
\hline 991 & 1174 & Myrcene & ND & ND & ND & ND & $30.6 \pm 0.7$ \\
\hline 1009 & 1157 & $\delta$-3-Carene & $0.5 \pm 0.3$ & $0.4 \pm 0.1$ & $0.5 \pm 0.0$ & $0.4 \pm 0.1$ & $0.5 \pm 0.0$ \\
\hline 1025 & 1203 & Limonene & $9.8 \pm 0.1$ & $7.5 \pm 0.2$ & $5.9 \pm 0.2$ & $5.6 \pm 0.2$ & $14.1 \pm 0.1$ \\
\hline 1057 & 1255 & $\gamma$-Terpinene & ND & $0.2 \pm 0.0$ & ND & $0.2 \pm 0.0$ & ND \\
\hline 1086 & 1265 & $\alpha$-Terpinolene & $0.2 \pm 0.0$ & $0.4 \pm 0.0$ & $0.2 \pm 0.0$ & $0.3 \pm 0.1$ & $0.2 \pm 0.0$ \\
\hline 1089 & 1282 & $p$-Cymenene & $0.1 \pm 0.0$ & $0.2 \pm 0.0$ & $0.2 \pm 0.0$ & $0.2 \pm 0.1$ & ND \\
\hline 1094 & 1392 & 2-Nonanone & $0.1 \pm 0.0$ & $0.1 \pm 0.0$ & ND & $0.1 \pm 0.0$ & $0.1 \pm 0.0$ \\
\hline 1096 & 1401 & Fenchone & ND & $0.1 \pm 0.0$ & ND & $0.1 \pm 0.0$ & ND \\
\hline 1117 & - & trans-p-Menth-2-en-1-ol & ND & $0.1 \pm 0.0$ & ND & ND & ND \\
\hline 1128 & 1487 & $\alpha$-Campholenal & $0.1 \pm 0.0$ & $0.1 \pm 0.0$ & $0.2 \pm 0.0$ & $0.1 \pm 0.0$ & ND \\
\hline 1138 & 1664 & trans-Pinocarveol & $0.5 \pm 0.0$ & $0.9 \pm 0.1$ & $1.7 \pm 0.1$ & $0.7 \pm 0.1$ & $0.1 \pm 0.0$ \\
\hline 1140 & 1663 & cis-Verbenol & $0.5 \pm 0.0$ & $0.5 \pm 0.0$ & $0.7 \pm 0.2$ & $0.3 \pm 0.1$ & $0.2 \pm 0.0$ \\
\hline 1145 & 1532 & Camphor & ND & $0.1 \pm 0.0$ & ND & ND & $0.0 \pm 0.0$ \\
\hline 1159 & 1535 & trans-Pinocamphone & ND & $0.1 \pm 0.0$ & $0.2 \pm 0.0$ & $0.1 \pm 0.0$ & ND \\
\hline 1165 & 1587 & Pinocarvone & ND & $0.1 \pm 0.0$ & ND & $0.2 \pm 0.0$ & ND \\
\hline 1167 & 1719 & Borneol & $0.1 \pm 0.0$ & $0.4 \pm 0.0$ & $0.2 \pm 0.0$ & $0.4 \pm 0.0$ & $0.2 \pm 0.0$ \\
\hline 1174 & 1611 & Terpinen-4-ol & $0.5 \pm 0.1$ & $1.0 \pm 0.0$ & $0.6 \pm 0.1$ & $0.6 \pm 0.1$ & $0.1 \pm 0.0$ \\
\hline 1185 & 1864 & $p$-Cymen-8-ol & $0.2 \pm 0.0$ & $0.3 \pm 0.0$ & $0.5 \pm 0.0$ & $0.3 \pm 0.1$ & $0.1 \pm 0.0$ \\
\hline 1201 & 1706 & $\alpha$-Terpineol & $1.8 \pm 0.1$ & $2.01 \pm 0.1$ & $2.8 \pm 0.1$ & $2.7 \pm 0.1$ & $0.2 \pm 0.0$ \\
\hline 1205 & 1731 & Verbenone & $0.3 \pm 0.0$ & $0.6 \pm 0.1$ & $0.7 \pm 0.1$ & $0.4 \pm 0.1$ & $0.1 \pm 0.0$ \\
\hline 1217 & 1845 & trans-Carveol & $0.1 \pm 0.0$ & $0.1 \pm 0.0$ & $0.3 \pm 0.1$ & $0.3 \pm 0.0$ & ND \\
\hline 1238 & 1607 & Thymol methyl ether & $0.1 \pm 0.0$ & ND & $0.3 \pm 0.0$ & $0.1 \pm 0.0$ & ND \\
\hline 1241 & 1752 & Carvone & $0.2 \pm 0.0$ & $0.1 \pm 0.0$ & $0.4 \pm 0.0$ & $0.2 \pm 0.0$ & $0.1 \pm 0.0$ \\
\hline 1284 & 1597 & Bornyl acetate & $2.3 \pm 0.2$ & $0.9 \pm 0.1$ & $0.5 \pm 0.1$ & $1.3 \pm 0.6$ & $0.6 \pm 0.1$ \\
\hline 1300 & 1661 & trans-Pinocarvyl acetate & $0.2 \pm 0.0$ & $0.2 \pm 0.1$ & $0.4 \pm 0.1$ & $0.2 \pm 0.0$ & ND \\
\hline 1328 & 1698 & Myrtenyl acetate & $0.1 \pm 0.0$ & $0.1 \pm 0.0$ & $0.2 \pm 0.0$ & ND & ND \\
\hline 1378 & 1497 & $\alpha$-Copaene & ND & ND & ND & $0.6 \pm 0.2$ & ND \\
\hline 1379 & 1765 & Geranyl acetate & $0.5 \pm 0.1$ & $0.2 \pm 0.0$ & ND & $0.1 \pm 0.0$ & ND \\
\hline 1416 & 1612 & $\beta$-Caryophyllene & $0.1 \pm 0.0$ & ND & $0.2 \pm 0.1$ & $0.1 \pm 0.0$ & $1.0 \pm 0.1$ \\
\hline 1457 & 1689 & $\beta$-Farnesene & $1.9 \pm 0.1$ & $0.5 \pm 0.0$ & $4.0 \pm 0.0$ & $0.3 \pm 0.0$ & $01.0 \pm 0.1$ \\
\hline 1500 & 1740 & $\alpha$-Muurolene & ND & ND & ND & $0.1 \pm 0.0$ & $0.1 \pm 0.0$ \\
\hline 1513 & 1776 & $\gamma$-Cadinene & $0.1 \pm 0.0$ & $0.2 \pm 0.0$ & ND & $0.1 \pm 0.0$ & ND \\
\hline 1526 & 1773 & $\delta$-Cadinene & ND & $0.2 \pm 0.0$ & ND & ND & ND \\
\hline 1581 & 2008 & Caryophyllene oxide & ND & ND & $0.2 \pm 0.0$ & $0.2 \pm 0.0$ & $0.2 \pm 0.1$ \\
\hline 1653 & 2256 & $\alpha$-Cadinol & $0.2 \pm 0.0$ & $0.2 \pm 0.0$ & $0.2 \pm 0.0$ & ND & ND \\
\hline 1668 & 2020 & $\beta$-Bisabolol & $0.2 \pm 0.1$ & ND & ND & $0.1 \pm 0.0$ & ND \\
\hline 1724 & 1946 & Farnesol & ND & ND & ND & ND & $0.2 \pm 0.1$ \\
\hline 1948 & - & Cembrene & ND & ND & ND & ND & $0.1 \pm 0.1$ \\
\hline 1974 & 2408 & Sclarene & $4.7 \pm 0.0$ & $1.1 \pm 0.1$ & $5.5 \pm 0.2$ & $4.0 \pm 0.1$ & $2.6 \pm 0.1$ \\
\hline 2057 & 2525 & Abieta-8,11,13-triene & $7.0 \pm 0.2$ & $7.7 \pm 0.3$ & $10.2 \pm 0.7$ & $3.0 \pm 0.2$ & $2.2 \pm 0.5$ \\
\hline 2060 & 2438 & Kaur-16-ene & $7.1 \pm 0.1$ & $4.7 \pm 0.5$ & $7.5 \pm 0.1$ & $7.1 \pm 0.1$ & $3.5 \pm 0.1$ \\
\hline 2098 & - & Abieta-7,13-diene & $3.4 \pm 0.0$ & $1.9 \pm 0.1$ & $7.5 \pm 0.3$ & $3.2 \pm 0.1$ & $4.7 \pm 0.8$ \\
\hline 2268 & - & Dehydroabietal & $0.9 \pm 0.0$ & $0.9 \pm 0.0$ & $1.7 \pm 0.0$ & $0.5 \pm 0.0$ & $0.8 \pm 0.6$ \\
\hline \multirow[t]{7}{*}{2274} & - & $\beta$-Cembrenediol & $1.5 \pm 0.0$ & $1.2 \pm 0.4$ & $4.2 \pm 0.2$ & $0.4 \pm 0.1$ & $2.6 \pm 0.1$ \\
\hline & & Monoterpene hydrocarbons & 60.7 & 73.1 & 48.9 & 71.7 & 79.0 \\
\hline & & Oxygenated monoterpenes & 7.4 & 7.9 & 9.7 & 8.2 & 1.7 \\
\hline & & Sesquiterpene hydrocarbons & 2.1 & 0.9 & 4.2 & 1.3 & 2.1 \\
\hline & & Oxygenated sesquiterpenes & 0.3 & 0.2 & 0.4 & 0.3 & 0.4 \\
\hline & & Others & 24.7 & 17.7 & 36.6 & 18.4 & 16.6 \\
\hline & & Total & 95.2 & 99.8 & 99.8 & 99.9 & 99.8 \\
\hline
\end{tabular}

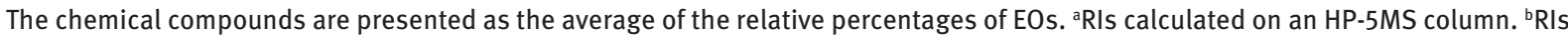
calculated on an HP Innowax column. ND, Not detected. 


\subsubsection{Essential oil chemical variability according to the geographical origin}

For the purpose of detecting a potential impact of harvesting sites on the accumulation of the main terpene metabolites in EO of $C$. libani from cones, which may lead to specific oil chemical compositions, one-way ANOVA test (SPSS 16.0 software) was applied in order to evaluate the existence of significant correlations between EO main components of cedar cones and the geographical location of harvest and to estimate the optimal harvesting site of C. libani, providing the optimal EO mixture corresponding to a required activity according to user's need.

One-way ANOVA test showed that EO chemical composition varied considerably according to the geographical location of harvest $(\mathrm{p}<0.05)$.

Our study revealed the dominance of $\alpha$-pinene in all the samples collected from the different Lebanese sites. In Chouf reserve, we noted the highest $\alpha$-pinene contents.

$\beta$-Pinene amounts significantly fluctuated among the regions and were higher in the samples collected from Ehden reserve, while the lowest values of $\beta$-pinene were noticed in Qartaba $(\mathrm{p}<0.05)$.

Limonene levels were significantly lower in Tannourine and Chouf, while this compound predominated in the EO of the cones harvested from Qartaba $(\mathrm{p}<0.05)$.

The region of harvest largely affected myrcene $(\mathrm{p}<0.05)$. A statistically significant difference in $\alpha$-terpineol contents was noted between the regions $(\mathrm{p}<0.05)$; the highest values were noticed in Tannourine and Chouf, whereas we registered the lowest levels in Qartaba.

Bornyl acetate amounts significantly varied between the locations $(\mathrm{p}<0.05)$ and prevailed in the samples harvested from Bsharri and Chouf compared to the other sites.

Geographical location significantly affected sclarene, kaur-16-ene, abieta-8,11,13-triene, and abieta-7,13diene levels $(p<0.05)$. Sclarene and kaur-16-ene reached their minimum values in Ehden reserve and Qartaba. The samples collected from Chouf reserve and Qartaba were characterized by their lowest abieta-8,11,13-triene amounts, whereas the samples harvested from Tannourine were distinguished by their wealth in this component. The lowest values of abieta-7,13-diene were recorded in Ehden and the highest ones in Tannourine.

Geographical locations influenced the contents of $\beta$-farnesene and $\beta$-cembrenediol $(\mathrm{p}<0.05)$. Their amounts were significantly higher in Tannourine compared to the other provenances. The lowest values of $\beta$-farnesene were observed in Ehden and Chouf reserves and in Chouf reserve for $\beta$-cembrenediol.

\subsubsection{Chemical variability of $C$. libani cones EOs according to geographical origin - comparison with the literature}

In order to assess for the first time the existence of cedar cones EO chemical polymorphism within a group of samples collected from different geographical locations and to distinguish which constituent has signed the oil chemical identity in cedar cones EOs according to the provenance, PCA was conducted on all EO samples (Figure 1). Principal component analysis showed that the maximal amount of variance in the data and its direction are explained by the first two principal components PC1 and PC2, which extracted $72.01 \%$ and $10.92 \%$ of the total variance, respectively.

The first PC is mainly associated to $\alpha$-pinene witnessing the predominance of this compound in all the oil studied samples and marking its lowest values in Adana, Turkey (8) [24]. $\beta$-Pinene, limonene, abieta-8,11,13-triene and abieta-7,13-diene contributed to the definition of the first PC.

Significant concentrations of $\beta$-pinene distinguished predominantly Ehden (2) (our study), Chouf (4) (our study), Bsharri (1) (our study), Tannourine (3) (our study), and Bsharri (9) [27] oil samples, defining consequently the predominance of $\alpha$-pinene and $\beta$-pinene in these locations. Limonene, abieta-8,11,13-triene, and abieta-7,13-diene were identified in all samples at variable concentrations. It is noticeable that limonene, abieta-8,11,13-triene, and $\alpha$-pinene were the major compounds of Adana, Turkey, oil sample (8) [24]. The oil composition of Başkonuş District, Turkey (7) [25], although dominated by $\alpha$-pinene, exhibited the highest contents of abieta-7,13-diene and then characterized by $\alpha$-pinene and abieta-7,13-diene majority.

The second PC is mainly correlated to myrcene, exclusively detected in Qartaba (5), Hadath Eljebeh-Tannourine reserve (6) [8] and then Adana, Turkey (8) [24], Bsharri (9) [27], and Başkonuş District, Turkey (7) [25]. This compound was checked as the most abundant in Qartaba samples (5) and was also found in significant concentration in Hadath Eljebeh-Tannourine reserve (6) [8]. The oils collected from these two regions were distinguished from the others by their remarkable content of myrcene. Therefore, the prevalence of myrcene, $\alpha$-pinene, and limonene was marked in Qartaba (5), and $\alpha$-pinene and myrcene in Hadath Eljebeh-Tannourine reserve (6) [8].

In summary, we pointed out that the comparison of our results with those reported exhibited the occurrence of several EO types according to the region of harvest and provided a new insight into the chemical variability of cedar cones EOs. These results clearly indicate that 


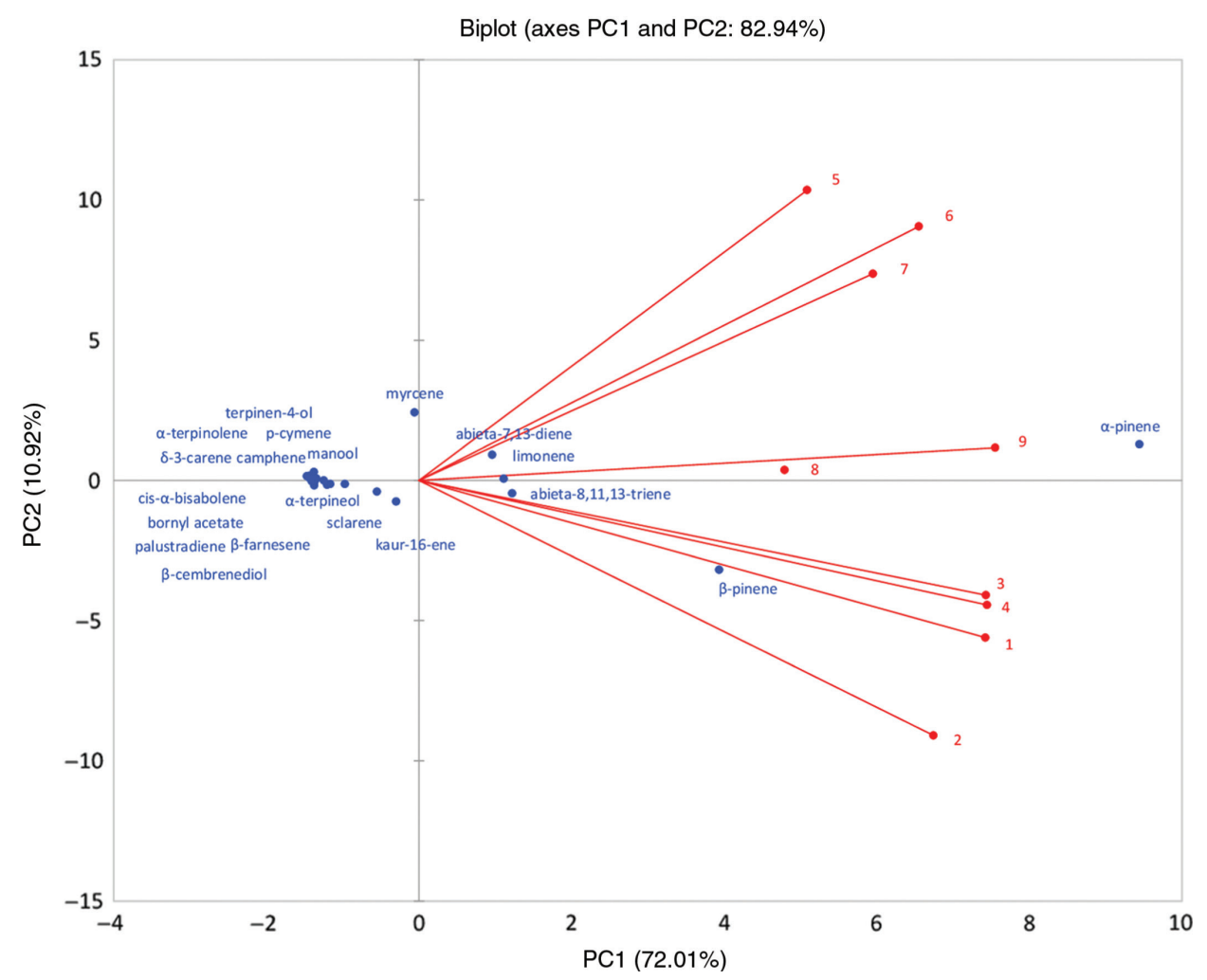

Figure 1: Principal component projection plot of PC1 and PC2 scores and loadings based on GC/MS data of cones EOs of $C$. libani collected from several geographical locations (our results and data extracted from literature). The numbers represent the samples collected from the different studied locations (our samples and data previously published). (1): Bsharri (our study), (2): Ehden (our study), (3): Tannourine (our study), (4): Chouf (our study), (5): Qartaba (our study), (6): Hadath Eljebeh-Tannourine reserve [8], (7): Başkonuş District, Turkey [25], (8): Adana, Turkey [24], (9): Bsharri [27].

biosynthesis of EO secondary metabolites is strongly influenced by geographical conditions: environmental factors of the different studied sites and cultivation conditions. Geographical location is associated to a number of environmental factors, such as precipitation, wind exposure, light intensity, UV radiation, high temperature and drought conditions, cold, frost, soil composition and fertility, and so on. The combination of all these factors puts pressure on the plants, with a need to develop mechanisms to be protected and to prevent damages. In fact, terpenoids are involved in specific adaptation strategies, such as defense against abiotic stresses and defense against pests and microorganisms [28]. Therefore, the variability observed in the accumulation of EO chemical compounds according to the region of harvest could be explained by the fact that specific compounds are mainly biosynthesized in a particular region in order to secure and protect the plant $[13,14,18,29]$. Furthermore, this variability could be attributed to both abiotic and abiotic factors. These results stress the importance of selecting a harvesting region ensuring the optimal EO chemical composition that best fits the market demands.

\subsubsection{Chemical variability according to cedar parts and extraction methods based on existing literature survey}

According to previous reports, sesquiterpenes characterized mainly wood EO of the biblical cedar of Lebanon. Therefore, Saab et al. [30] in 2012 evidenced the predominant presence of $\beta$ - (21.4\%), $\alpha$ - (9.5\%), and $\gamma$-himachalene $(6 \%)$ isomers together with himachalol $(5.6 \%), \gamma-(Z)$ atlantone (5\%), and allohimachalol (4.1\%).

Başer and Demirçakmak in 1995 proved that C. libani wood EOs from Antalya and İçel were, respectively, distinguished by the dominance of $\beta$ - (38.2\%-34.3\%), $\alpha$ - (12.8$11.5 \%)$, and $\gamma$-himachalene $(7.6 \%-6.8 \%)$ isomers with trans- $\alpha$-atlantone $(7.8 \%-14.8 \%)$, himachalol $(1.2 \%-8.8 \%)$, trans- $\beta$-atlantone $(1.4 \%-2.4 \%)$, $\beta$-cedrene $(1.8 \%-2.8 \%)$, allohimachalol $(1.8 \%-2.3 \%),(E)-10,11$-dihydroatlantone $(3.7 \%-0.02 \%)$, cis- $\beta$-atlantone $(1.1 \%-2.5 \%)$, and cis- $\alpha$ atlantone (1.06\%-2.1\%) [5]. Saab et al. [3] in 2005 demonstrated the predominance of himachalol (43.1\%) and $\gamma$ - (11.9\%), $\alpha-(7.12 \%)$, and $\beta$ - $(7 \%)$ isomers of himachalene and allohimachalol (3.92\%) in C. libani wood EO. In 
addition, they determined smaller amounts of the $(E)$ and $(Z)$ isomers of $\alpha-, \beta-$, and $\gamma$-atlantone. According to Loizzo et al. [9] in 2008, himachalol (22.5\%), $\beta$-himachalene (21.9\%), $\alpha$-himachalene (10.5\%), and $\gamma$-himachalene (9.1\%) were considered as peculiar of cedar wood EO.

Cedrus libani root EOs from İçel were characterized by the presence of $\beta$ - (27.5\%), $\alpha$ - (10.3\%), and $\gamma$-himachalene $(7.1 \%)$ isomers with trans- $\alpha$-atlantone $(23.7 \%)$, himachalol (9.7\%), trans- $\beta$-atlantone (2.3\%), $\beta$-cedrene $(1.1 \%)$, allohimachalol (2.2\%), (E)-10,11-dihydroatlantone (0.1\%), cis- $\beta$ atlantone (2.3\%), and cis- $\alpha$-atlantone (2.8\%) [5].

Limonene $(17.7 \%)$ was the main compound in the EO obtained from the cones of $C$. libani natively grown in Turkey, followed by abieta-8,11,13-triene (17\%) and $\alpha$-pinene $(12.3 \%)$. Limonene is used as an antimicrobial inhibitor in the food industry [24]. The chemical profile of EO from the oleoresin of the cones of $C$. libani grown in Turkey was distinguished by the preponderance of $\alpha$-pinene (24.8\%), abieta-7,13-diene (16.7\%), abieta-8,11,13triene (6.9\%), manool (5.8\%) and terpinen-4-ol (3.7\%), $\alpha$-terpineol (3.4\%), p-cymene (2.9\%), and limonene (2.7\%) [25]. The investigation of the phytochemical composition of $C$. libani ethanol extract obtained from cones illustrated the dominance of $\alpha$-pinene (51\%), $\beta$-myrcene $(13 \%)$, 7,13-abietadiene (3.2\%), terpinolene (3.1\%), and limonene (2.3\%) [9].

Manool (11.0\%) predominated in the hydrodistilled EOs of the C. libani trunk-bark samples [31].

Saab et al. [32] in 2011 reported that the main components of $C$. libani seed chloroform extracts were $\alpha$ - and $\beta$-pinene $(34.4 \% \pm 1.22 \%$ and $33.3 \% \pm 1.08 \%$, respectively). The occurrence of fatty acids and ethers as most abundant compounds, in particular oleic acid (17.3\% $\pm 1.34 \%)$, methyl oleate $(7.8 \% \pm 0.42 \%)$, and ethyl oleate $(5.3 \% \pm 0.48 \%)$, in C. libani seed ethanol extract has been evidenced. Diterpenes, as neoabietol $(11.8 \% \pm 0.98 \%)$, abieta-7,13-diene (8\% $\pm 0.46 \%)$, abieta-8(14), 13(15)-diene (7.9\% $\pm 0.66 \%)$, abietol $(6 \% \pm 0.55 \%)$, and abietal $(2 \% \pm 0.13 \%)$, were also detected [32, 33].

For what concerns cedar leaves ethanol extract, germacrene D was checked as the most abundant compound (29.4\%) [9]. It was found that fenchone (14.2\%), $\beta$-thujone (28\%), $\alpha$-thujone $(20.3 \%)$, camphor (8.7\%), 1-borneol (4.7\%), and endobornyl acetate (4\%) were the main constituents in cedar leaf EOs [34].

Based on a PCA, a comparison of the main components (> 5\%) of $C$. libani extracts, extracted from different parts (wood, roots, leaves, trunk-bark, seeds, and cones) and by different extraction methods (hydrodistillation, steam distillation, chloroform, and ethanol extraction), assessing our results and those previously published, is illustrated in Figure 2. Two PCs were chosen representing more than $62.29 \%$ of the variability. Principal component analysis results revealed the presence of three groups.

Cedar cones EOs, extracted by hydrodistillation (12, $13,14,15,16)$ (our study), (17) [8], (18) [25], (19) [24], and (20) [27], and seed chloroform extract samples (10) [32] distributed in a group were clearly separated from the two other groups by the first principal component (PC1). These samples constituting the first cluster possessed in common high relative amounts of $\alpha$-pinene, $\beta$-pinene, and then abieta-8,11,13-triene, myrcene, limonene, sclarene, palustradiene, and kaur-16-ene. $\alpha$-Pinene and $\beta$-pinene are known to have antibacterial, antioxidant, anti-inflammatory, and anticarcinogenic activities [10, 18, 35-41].

A clear separation of the second cluster representing oils extracted from cedar wood $(1,2)$ [5], (3) [30], (4) [3], and (5) [9] and roots (6) [5] from the first cluster (cedar cones EOs and seed chloroform extract samples) is shown along PC1. This second cluster is separated from the third one by PC2 and characterized by high amounts of $\beta$-himachalene, $\alpha$-himachalene, $\gamma$-himachalene, trans- $\alpha$ atlantone, and himachalol. Principal component analysis allowed us to draw the following conclusions: cedar wood and root EOs had identical main components, and the relative concentration of these components was similar by both extraction methods: steam distillation and hydrodistillation.

The third cluster was separated from the group of seed chloroform extract and cedar cones EO samples by PC1 and from the group of wood and root EO samples by PC2. This cluster contained cedar leaves ethanol extract (7) [9], cedar leaves EO (8) [34], cedar EO from trunk-bark (9) [31], and cedar seed ethanol extract (11) [32] samples and was dominated by $\beta$-thujone, $\alpha$-thujone, camphor, fenchone, $\beta$-caryophyllene, germacrene $D, \delta$-cadinene, trans$\alpha$-bisabolene, 1-epi-cubenol, isolongifolene, manool, methyl oleate, oleic acid, ethyl oleate, abietol, neoabietol, abieta-7,13-diene, and abieta-8(14),13(15) diene.

According to PCA, seed ethanol extraction and seed chloroform extraction affected the chemical composition of seed extracts given the fact that different compounds were recovered after these two extraction methods.

These findings shed light on the cedar extract chemical polymorphism. Given the fact that each part of the same plant does not possess the same enzymatic equipment, the metabolomic profile is strongly dependent on plant parts or organs [42]. Extraction methods, extrinsic conditions, and interspecific and intraspecific factors also influenced plant extract chemical composition [14-16, 43-45]. 


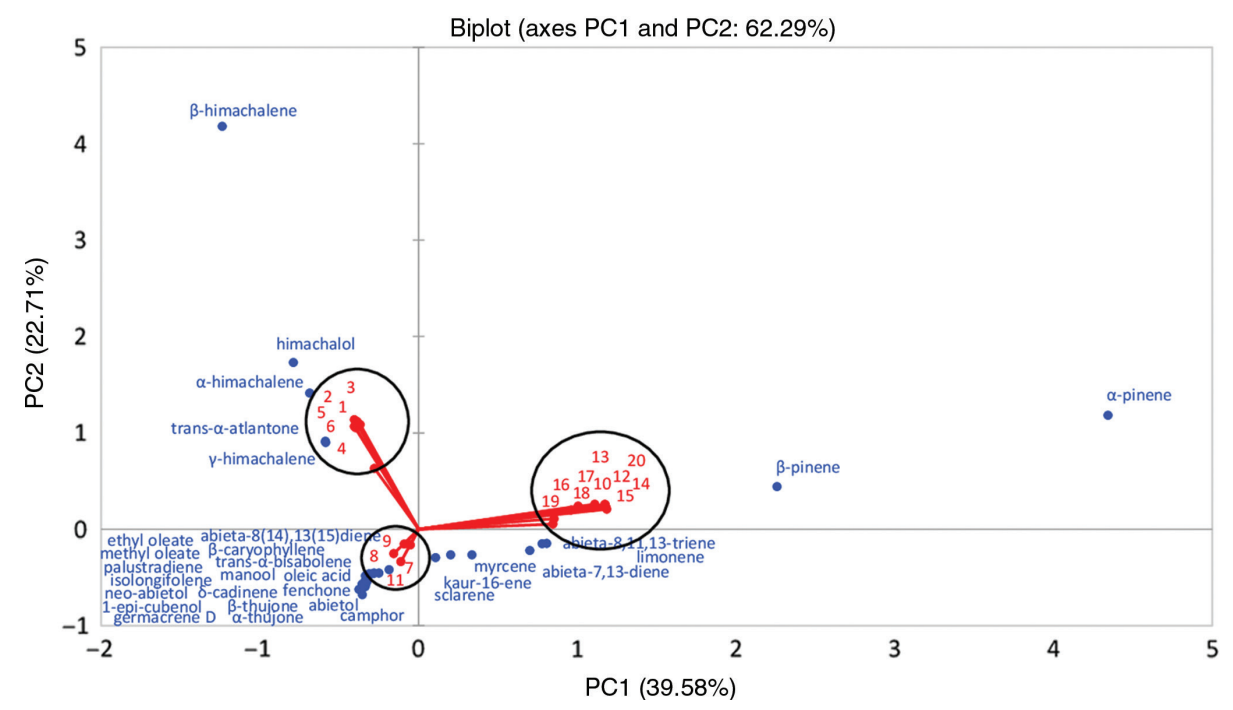

Figure 2: Principal component projection plot of PC1 and PC2 scores and loadings based on GC/MS data of $C$. libani extracts extracted from different parts (our results and data previously published). The numbers represent the samples extracted from the different studied $C$. libani parts (our samples and data previously published). (1): C. libani wood EO from Antalya, steam hydrodistillation [5]; (2): C. libani wood EO from Tarsus, steam hydrodistillation [5]; (3): C. libani wood EO, hydrodistillation [30]; (4): C. libani wood EO, hydrodistillation [3]; (5): C. libani wood EO, hydrodistillation [9]; (6): C. libani root EO from Tarsus, steam hydrodistillation [5]; (7): C. libani leaves ethanol extract [9]; (8): C. libani leaves EO [34]; (9): C. libani trunk-bark EO [31]; (10): C. libani seed chloroform extract [32]; (11): C. libani seed ethanol extract [32]; (12): C. libani cones EO from Bsharri, hydrodistillation (our study); (13): C. libani cones EO from Ehden, hydrodistillation (our study); (14): C. libani cones EO from Tannourine, hydrodistillation (our study); (15): C. libani cones EO from Chouf, hydrodistillation (our study); (16): C. libani cones EO from Qartaba, hydrodistillation (our study); (17): C. libani cones EO, hydrodistillation [8]; (18): C. libani cones EO, hydrodistillation [25]; (19): C. libani cones EO, hydrodistillation [24]; (20): C. libani cones EO, hydrodistillation [27].

\section{Conclusion}

Bearing in mind that $C$. libani is the sacred tree constituting the symbol of Lebanon, the results of this study contribute to a scientific valorization of this majestic tree anchored in beliefs and traditions. This first report bringing to light the chemical variability of EOs from the cones of cedars growing wild at four Lebanese natural reserves and protected areas (Bsharri, Chouf, Ehden, and Tannourine) and from cones of a cultivated cedar growing in Qartaba evidenced the existence of polymorphism in relation to the geographical location.

In light of this observation, our results affirm the variability of $C$. libani cones EOs depending on the geographical location and suggest the involvement of abiotic and biotic factors. Knowing that a better understanding of EO chemical variability in response to abiotic pressures is capital in the perspective of identifying new bioactive molecules and envisaging pharmacological activities of plants, our findings can be at the service of the determination of the best harvest locations in order to optimize growing and harvest conditions for optimal EO quality and quantity according to the market requirements.
In addition, a review of the existing literature on C. libani extracts composition allowed us to draw a relationship between chemical composition and cedar part, on the one hand, and chemical composition and extraction method. Further variability studies conducted on extracts of wild and cultivated $C$. libani according to seasonal variations, genetics, and soil composition should be considered in future investigations to further explore the chemical polymorphism.

Acknowledgments: We are grateful for the support from CNRS Lebanon.

\section{References}

1. Global Fire Monitoring Center. Forest fire threat in qadisha valley. Lebanon: Precautionary Action to Prevent Damage or Destruction of the UNESCO World Heritage Site. Paris, France and Beirut, Lebanon: GFMC and UNESCO. Report of an Initial Project, submitted to UNESCO by the Global Fire Monitoring Center (GFMC), 2010.

2. Cetin H, Kurt Y, Isik K, Yanikoglu A. Larvicidal effect of Cedrus libani seeds oils on mosquito Culex pipens. Pharm Biol 2009;47:665-8. 
3. Saab AM, Harb FY, Koenig WA. Essential oil components in heart wood of Cedrus libani and Cedrus atlantica from Lebanon. Minerva Biotecnol 2005;17:159-61.

4. Musselman LJ. Trees in the Koran and the Bible. Unasylva 2003;54:45-52.

5. Başer KH, Demirçakmak B. The essential oil of Taurus cedar (Cedrus libani A. Rich): recent results. Chem Nat Compd 1995;31:16-20.

6. Kurt Y, Kaçar MS, Isik K. Traditional tar production from Cedrus libani A. Rich on the Taurus Mountains in Southern Turkey. Econ Bot 2008;62:615-20.

7. Chaney W, Basbous M. The Cedars of Lebanon witnesses of history. Econ Bot 2010;32:118-23.

8. Loizzo MR, Saab AM, Statti GA, Menichini F. Composition and $\alpha$-amylase inhibitory effect of essential oils from Cedrus libani. Fitoterapia 2007;8:323-6.

9. Loizzo MR, Saab AM, Lampronti I, Gambari R, Menichini F, Cinatl J, et al. Phytochemical analysis and in vitro evaluation of the biological activity against herpes simplex virus type1 (HSV1) Cedrus libani essential oil. Phytomedicine 2008;15:79-83.

10. Chaudhary AK, Ahmad S, Mazumder A. Isolation, structural elucidation and in vitro antioxidant activity of compounds of chloroform extract of Cedrus deodara (Roxb.) Loud. Nat Prod Res 2015;29:268-73.

11. Skočibušić M, Bezić N, Dunkić V. Variability of Satureja cuneifolia Ten. essential oils and their antimicrobial activity depending on the stage of development. Eur Food Res Technol 2004;218:367-71.

12. Karousou R, Koureas DN, Kokkini S. Essential oil composition is related to the natural habitats: Coridothymus capitatus and Satureja thymbra in NATURA 2000 sites of Crete. Phytochemistry 2005;66:2668-73.

13. Dardioti A, Hanlidou E, Lanaras T, Kokkini S. The essential oils of the Greek endemic Satureja horvatii ssp. macrophylla in relation to bioclimate. Chem Biodivers 2010;7:1968-77.

14. Zgheib R, Chaillou S, Ouaini N, Kassouf A, Rutledge DN, Azzi $D$, et al. Chemometric tools to highlight the variability of the chemical composition and yield of Lebanese Origanum syriacum L. essential oil. Chem Biodivers 2016;13:1326-47.

15. Zgheib R, Chaillou S, Ouaini N, Rutledge DN, Stien D, Kassouf A, et al. Investigation of Origanum libanoticum Boiss. essential oils chemical polymorphism by independent components analysis (ICA). Nat Prod Commun 2019;13:1731-40.

16. Zgheib R, El Beyrouthy M, Chaillou S, Ouaini N, Rutledge DN, Stien D, et al. Chemical Variability of the Essential Oil of Origanum ehrenbergii Boiss. growing wild in Lebanon. Int J Mol Sci 2019;20:1026.

17. Zgheib R, Yassine C, Azzi-Achkouty S, El Beyrouthy M. Investigation of essential oil chemical polymorphism of Salvia fruticosa naturally growing in Lebanon. J Essent Oil Bear Plants 2019;22:408-30.

18. Sharma S, Bhatt V, Kumar N, Singh B, Sharma U. Locational comparison of essential oil from selected conifers of Himachal Pradesh. Nat Prod Res 2017;31:1578-82.

19. Mouterde P. Nouvelle Flore du Liban et de la Syrie. Beyrouth, Liban: Distribution Librairie Orientale, 1983.

20. European Pharmacopoeia, 3rd ed. Strasbourg, France: Council of Europe Publishing, 1997.

21. Jennings W, Shibamoto T. Qualitative analysis of flavour and fragrance volatiles by glass capillary gas chromatography. New York: Academic Press, 1980.
22. Adams RP. Identification of Essential Oil Components by Gas Chromatography/Mass Spectrometry, 4th ed. Carol Stream, IL: Allured Publishing Co., 2007.

23. Davies NW. Gas chromatographic retention indices of monoterpenes and sesquiterpenes on methyl silicon and carbowax 20M phases. J Chromatogr A 1990;503:1-24.

24. Tumen I, Hafizoglu H, Kilic A, Dönmez IE, Sivrikaya H, Reunanen $M$. Yields and constituents of essential oil from cones of Pinaceae spp. natively grown in Turkey. Molecules 2010;15:5797-806.

25. Yilmaz N, Alma MH, Nitz S, Kollmannsberger H, Efe FT. Chemical composition of the essential oils from oleoresin on cones of Cedrus libani. Asian J Chem 2005;17:2300-6.

26. Yavari A, Nazeri V, Sefidkon F, Hassani ME. Influence of some environmental factors on the essential oil variability of Thymus migricus. Nat Prod Commun 2010;5:943-8.

27. Fahed L, Khoury M, Stien D, Ouaini N, Eparvier V, El Beyrouthy M. Essential oils composition and antimicrobial activity of six conifers harvested in Lebanon. Chem Biodivers 2017;14:e1600235.

28. Sharaby A. Anti-insect properties of the essential oil of lemon grass, Cymbopogon citratus against the lesser cotton leafworm Spodoptera exigua (Hbn). Int J Trop Insect Sci 1988;9:77-80.

29. Galeş RC, Preotu A, Necula R, Gille E, Toma C. Altitudinal variations of morphology, distribution and secretion of glandular hairs in Origanum vulgare L. leaves. Stud Univ "Vasile Goldis". Ser Stiintele Vietii 2010;20:59-62.

30. Saab AM, Guerrini A, Sacchetti G, Maietti S, Zeino M, Arend J, et al. Phytochemical analysis and cytotoxicity towards multidrug-resistant leukemia cells of essential oils derived from Lebanese medicinal plants. Planta Med 2012;78:1-5.

31. Kolayli S, Ocak M, Aliyazicioglu R, Karaoglu S. Chemical analysis and biological activities of essential oils from trunk-barks of eight trees. Asian J Chem 2009;21:2684-94.

32. Saab AM, Lampronti I, Grandini A, Borgatti M, Finotti1 A, Sacchetti $\mathrm{G}$, et al. Antiproliferative and erythroid differentiation activities of Cedrus libani seed extracts against K562 human chronic myelogenus leukemia cells. Int J Pharm Biol Arch 2011;2:1658-62.

33. Nebi B, Ayse BA. Essential oil in Taurus cedar (Cedrus libani A. Rich) Seeds. J Essent Oil Bear Plants 2013;16:538-44.

34. Manoharan RK, Lee JH, Lee J. Antibiofilm and antihyphal activities of cedar leaf essential oil, camphor, and fenchone derivatives against Candida albicans. Front Microbiol 2017;8:1476.

35. Jiang Y, Wu N, Fu YJ, Wang W, Luo M, Zhao CJ, et al. Chemical composition and antimicrobial activity of the essential oil of rosemary. Environ Toxicol Pharmacol 2011;32:63-8.

36. Rivas da Silva AC, Lopes PM, Barros de Azevedo MM, Costa DC, Alviano CS, Alviano DS. Biological activities of $\alpha$-pinene and $\beta$-pinene enantiomers. Molecules 2012;17:6305-16.

37. Bakarnga-Via I, Hzounda JB, Fokou PV, Tchokouaha LR, GaryBobo M, Gallud A, et al. Composition and cytotoxic activity of essential oils from Xylopia aethiopica (Dunal) A. Rich, Xylopia parviflora (A. Rich) Benth. and Monodora myristica (Gaertn) growing in Chad and Cameroon. BMC Complement Altern Med 2014;14:125.

38. Li YL, Yeung CM, Chiu L, Cen YZ, Ooi VE. Chemical composition and antiproliferative activity of essential oil from the leaves of a medicinal herb, Schefflera heptaphylla. Phytother Res 2009; 23:140-2. 
39. Chen W, Liu Y, Li M, Mao J, Zhang L, Huang R, et al. Anti-tumor effect of $\alpha$-pinene on human hepatoma cell lines through inducing G2/M cell cycle arrest. J Pharmacol Sci 2015;127:332-8.

40. Salminen A, Lehtonen M, Suuronen T, Kaarniranta K, Huuskonen J. Terpenoids: natural inhibitors of NF- $\mathrm{KB}$ signalling with anti-inflammatory and anticancer potential. Cell Mol Life Sci 2008;65:2979-99.

41. Neves A, Rosa S, Gonçalves J, Rufino A, Judas F, Salgueiro L, et al. Screening of five essential oils for identification of potential inhibitors of IL-1 induced NF- $\mathrm{KB}$ activation and NO production in human chondrocytes: characterization of the inhibitory activity of $\alpha$-pinene. Planta Med 2010;76:303-8.
42. Bruneton J. Pharmacognosie: Phytochimie, Plantes Médicinales, 4th ed. Paris, France: Tec \& Doc, Lavoisier, 2009.

43. Economakis C, Skaltsa H, Demetzos C, Sokovic M, Thanos CA. Effect of phosphorus concentration of the nutrient solution on the volatile constituents of leaves and bracts of Origanum dictamnus. J. Agric. Food Chem 2002;50:6276-80.

44. Sefidkon F, Abbasi K, Khaniki GB. Influence of drying and extraction methods on yield and chemical composition of the essential oil of Satureja hortensis. Food Chem 2006;99:19-23.

45. Paula JA, Ferri PH, Bara MT, Tresvenzol LM, Sá FA, Paula JR. Infraspecific chemical variability in the essential oils of Pimenta pseudo-caryophyllus (Gomes) L.R. Landrum (Myrtaceae). Biochem Syst Ecol 2011;39:643-50. 